\title{
Dubai, the sustainable, smart city
}

\author{
Riadh AL-Dabbagh ${ }^{*}$ \\ Ajman University, Ajman, UAE
}

Received: 15 July 2021 / Received in final form: 21 October 2021 / Accepted: 21 October 2021

\begin{abstract}
Over the years, Dubai - UAE has achieved undoubtedly fascinating development in city styles and construction. The desert has been transferred to an advanced modern city with the tallest buildings in a considerable time. It has always encouraged achieving healthy and sustainable development in all sectors, explicitly building construction. It has and still working towards maintaining the balance between socioeconomic development and environmental protection. It has been announced and put within the national vision that it is of priority for the Government to transform Dubai into a smart city with an eco-friendly economy. This is under the aim to make it the most sustainable city in the world by 2021 . The other Emirates are also trying to build their own fully sustainable cities. A sustainable plan is "a building that reduces its environmental impact by decreasing energy and water use and reducing the waste production. Dubai's Green Building Regulations and Specifications encourage all contractors to build toward an eco-friendlier tomorrow, maintaining the future cohorts without negatively impacting the resident's health. It covers a wide range of topics related to green building design, including ecology planning, building vitality, resource efficiency in energy, water, materials, and waste management. Dubai has made the environment a part of its overall strategic plan, including many subplans, initiatives, and projects to improve the emirate's environmental conditions and reduce energy use. Dubai's strategic plan to become a green metropolis includes green buildings and green building materials. The difficulties that sustainable urban development presents are considerable. They are working on various techniques to lead today's urbanisation toward sustainability, including urban planning, transportation infrastructure, quality of life, and renewable energy use, to name a few. Green construction and green towns are part of a long-term national drive in the UAE to promote a green economy with the tagline "A green economy for sustainable development". This paper is highlighting the advanced initiatives, technologies, materials, strategies, difficulties and challenges that Dubai has been through to achieve sustainable smart city goals.
\end{abstract}

\section{Introduction}

The Green Buildings Regulations and Specification were declared required for governmental buildings in January 2011 and voluntary for private ones. The municipality made the standards mandatory for all new buildings in Dubai in March 2014, after 44 green governmental buildings had been built. The green buildings regulations and specifications address different aspects of green building design, such as ecology and planning, building vitality, energy, water, materials and waste [1].

By looking at end-use categories for energy, cleaner buildings and vehicle technologies must be focused on. In both cases, it is, of course, a choice between systems using carbon fuels and systems using clean electricity. Very simply, we need clean tech buildings, clean tech vehicles

\footnotetext{
* e-mail: riadhdabbagh46@gmail.com
}

and clean electricity generation. Promoting these three should be seen as most important when we ask, What should we do? [2].

The most proven non-carbon ways to generate electricity are solar energy, hydro generation and wind turbines. Equally important is conservation, using less energy while still heating and cooling buildings and keeping the lights on. As the world population grows, it may seem impossible to conserve energy, but we can adopt green building technologies [3].

This study is to explore the main factors that have contributed to the initiatives and practices implemented by Dubai for their journey toward a Sustainable and smart city.

\section{Buildings are the key}

Buildings produce more emissions than any other source, accounting for over half of our total energy consumption. They also have the potential to serve as a powerful 
reminder of the importance of change daily. Our ability to overcome the challenges that our world faces. The only human shelter will contribute more than any other project to the psychosocial impetus now required to change our collective direction toward a better tomorrow. Figure 1 shows the type of buildings developed in Dubai [4].

\section{The UAE Vision 2021}

The National Agenda of the UAE focuses on [5]:

- Improving the air quality

- Preserving water resources

- Increasing the contribution of clean energy

- Implementing green growth plans.

\section{Improving the air quality}

In cooperation with the General Secretariat of the Executive Council of Dubai, Dubai Municipality released the Dubai Air Quality Strategy 2017-2021. The approach aims to meet the National Agenda and Dubai Plan 2021 air quality targets (Fig. 2) [1].

Creating a national air emissions inventory will give meaningful, current, and comprehensive data on pollutant emissions. Maintaining an accurate, trustworthy, and extensive list is critical for informing future air quality control programmes. One of the aims of the vision 2021 of the UAE is to improve air quality, with the National Agenda aiming to raise air quality in the UAE to $90 \%$ by 2021 .

The project will be implemented in two phases in conjunction with the Global Green Growth Institute, GGGI. In the first phase, best practices and stakeholder consensus will be used to build a framework for an air emissions inventory for the UAE. The second phase will focus on developing a comprehensive national list that covers all central point, line, and area sources. Air Quality Index (AQI) is an artificial intelligence-based tool that monitors and analyses air quality in the UAE. The National Air Quality Platform uses the (AQI) platform to show information on air pollution.

\section{Preserving water resources}

Water is necessary for all life forms and is utilised for various functions in daily life and drinking. DEWA works relentlessly to increase its overall water production capacity, foresee future requirements and needs, and assure long-term sustainability to realise the wise leadership's vision. DEWA has established six focal areas in its water management strategy to increase the efficiency of water operations, correctly monitor water supplies, and reduce water losses [2], as in Figure 3.

An indicator monitors freshwater usage (including surface water, renewable water, and fossil water) as a percentage of overall renewable water in the UAE to assess water overuse. Desalination and wastewater treatment are weighted in the final result. Water Sustainability indicators were initiated. DEWA is committed to the efficient, effective, and cost-effective management of water resources

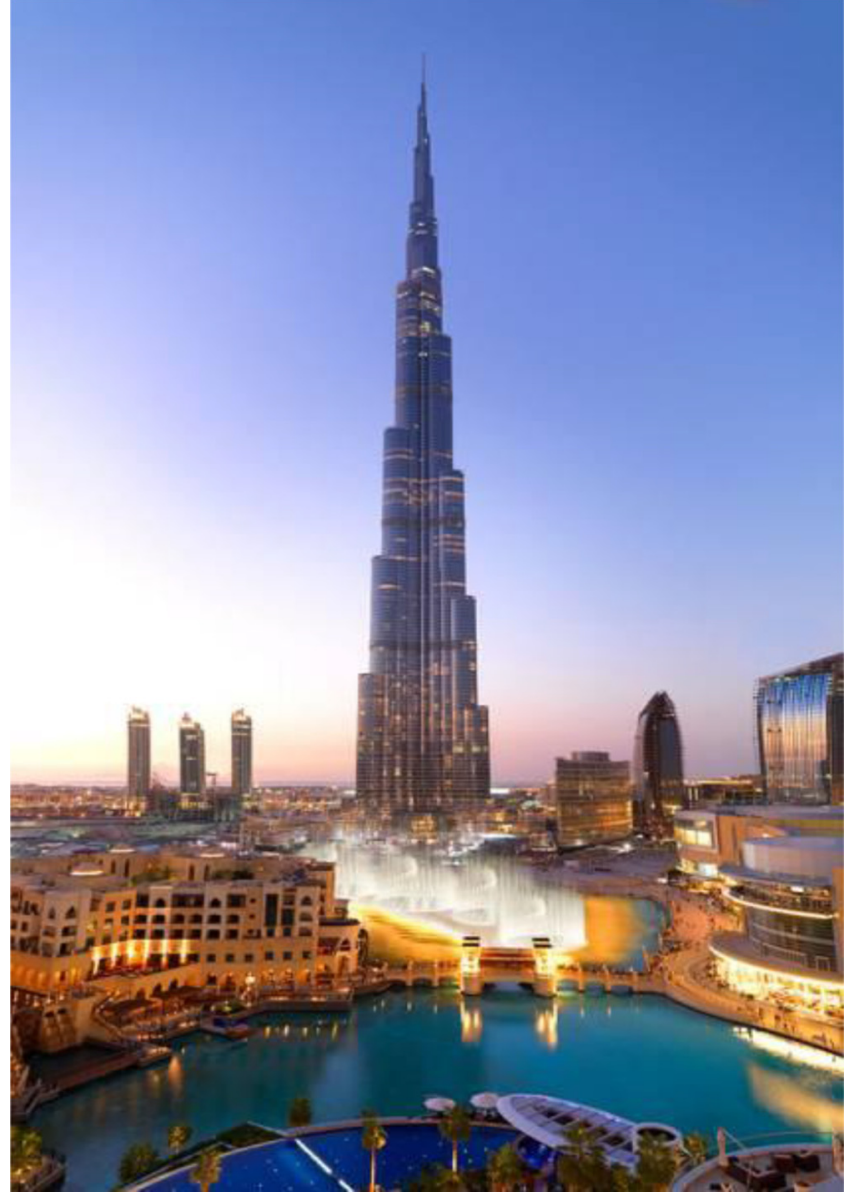

Fig. 1. Development of buildings in UAE.

through a set of rules and regulations as a leading sustainable creative global water corporation. The policies and regulations aim to promote sustainability concepts throughout the business performance, including water generation, transmission, and distribution. Continue to monitor and manage the most efficient use of its water resources by maintaining an innovative DEWA that adheres to a set of policies and regulations, which include, but are not limited to, the W\&C Asset Management Mechanism, the Electricity and Water Supply Policy, the Jebel Ali Power Station (JAPS) potable water specification, the GSO 149/2014 drinking water guidelines (Standardization Organization for GCC), and the World Health Organization (WHO) [2].

\section{Energy management and contribution of clean energy}

The UAE government aspires to strike a perfect balance between economic and social development by ensuring sustainable development while protecting the environment. DEWA's management strategy includes a commitment to guaranteeing the consistency of its electrical supply throughout Dubai. DEWA is investing in new 
AIR QUALITY STRATEGY TARGET 2021

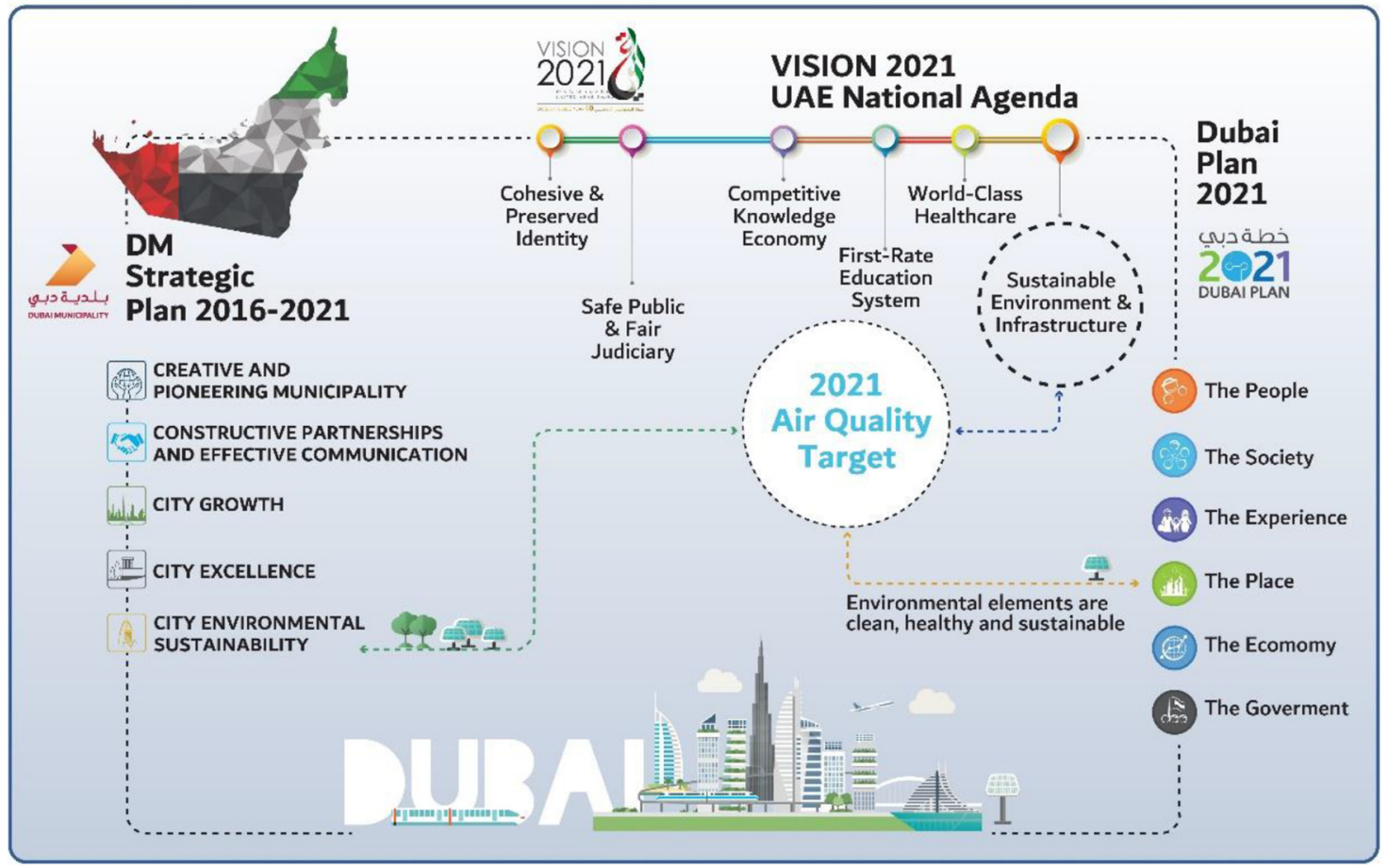

Fig. 2. Vision 2021 UAE National Agenda [1].

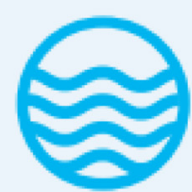

Water Production

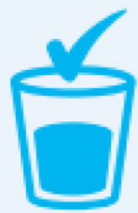

Water Quality

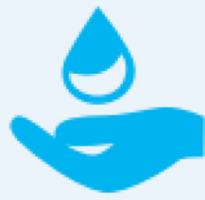

Customer Water Use

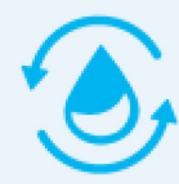

Whole Water

Cycle Approach

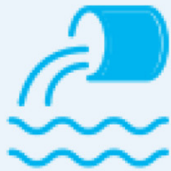

Production Wastewater

Discharge

Management

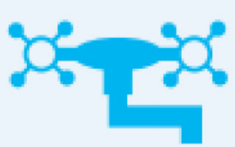

Water

Transmission and Distribution

Fig. 3. Focus areas in water management approached by DEWA [2].

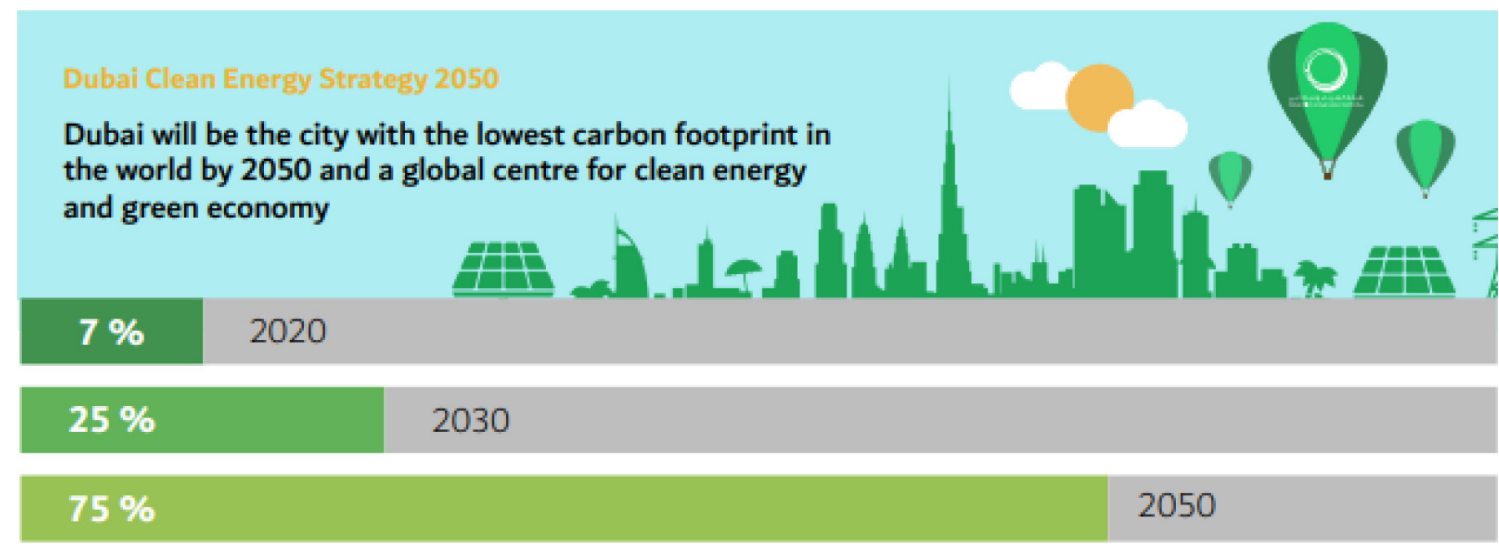

Fig. 4. Moving towards depending on renewable energy. 
- Designed and operates exactly as it was intended or even better

- Third party verified certification that helps owners measure and manage their properties

- Promotes healthy, durable, affordable, and environmentally-sound practices in building design \& construction

- Informational and helps guide decision making - nutrition label approach - in the built environment

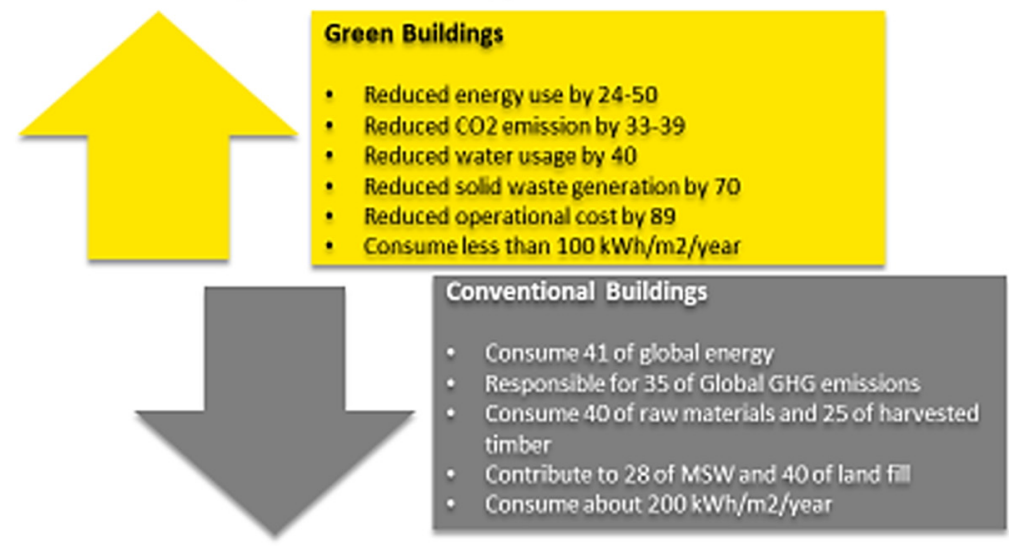

Fig. 5. Major achievements and approaches in transforming into a green economy.

\section{Designing "Green" doesn't mean "Green"}

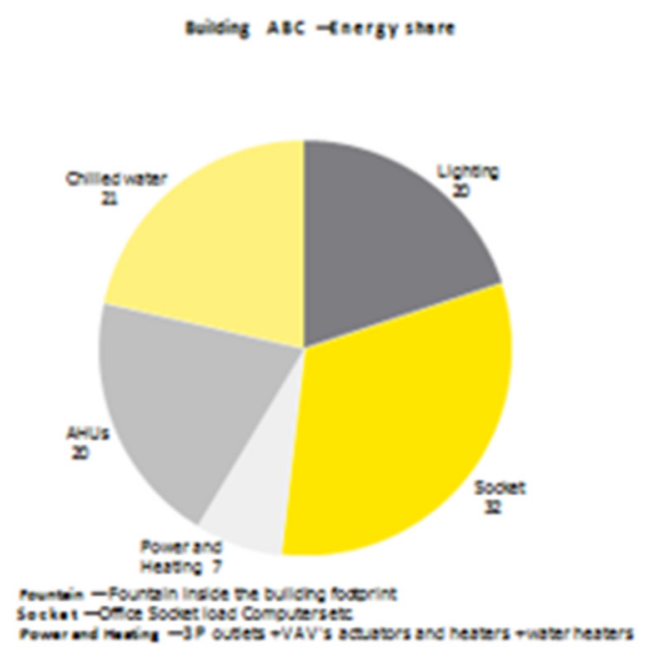

\begin{tabular}{|c|c|c|c|c|c|}
\hline \multirow{2}{*}{ Building } & \multicolumn{2}{|c|}{ Actual EUI } & \multicolumn{2}{|c|}{ Design EUI } & \multirow{2}{*}{$\begin{array}{c}\text { \%increase from } \\
\text { design }\end{array}$} \\
\hline & $\mathrm{x} w h / m 2$ & Sotw/5sq. ft & $k w / V / m 2$ & otw/ ssq. ft & \\
\hline Lighting & 85.32 & 27.05 & 34.05 & 10.79 & 150.8 \\
\hline Socket & 137.00 & 43.43 & 166.70 & 52.84 & $(17.8)$ \\
\hline $\begin{array}{l}\text { Power and } \\
\text { heating }\end{array}$ & 29.44 & 9.33 & 5.22 & 1.65 & 44.1 \\
\hline MCC-AHUs & 85.16 & 27.00 & 49.70 & 15.76 & 71.3 \\
\hline Fountain & $\cdot$ & - & - & - & 0 \\
\hline Chilled water & 92.06 & 29.18 & 83.63 & 26.51 & 10.1 \\
\hline Total & 428.97 & 135.98 & 339.30 & 107.56 & $26.4 \%$ \\
\hline
\end{tabular}

Fig. 6. Green building design based on an occupancy of total building capacity. technology, using international best practices, and continually enhancing its electricity generation, transmission, and distribution infrastructure to ensure this [2]. Energy issues are among the most serious and complex concerns that the world faces today. As part of the UN's Sustainable Development Goals, the UN has designated them "cheap and clean energy". To accomplish Dubai's sustainable growth, the UAE is trying to enhance the renewable and clean energy industry, reduce natural resource use, and identify alternate energy sources to traditional energy sources. This is why, in conjunction with the UAE Centennial 2071, UAE Vision 2021, and UAE Green Agenda, the Dubai Clean Energy Strategy 2050 was launched to provide $75 \%$ of Dubai's total power output from clean energy by 2050 and make Dubai the city with the lowest carbon footprint in the world [2]. Diversifying the energy mix minimises reliance on a single energy source, improving energy security while increasing the overall amount of power generated from clean energy sources to meet the Dubai Clean Energy Strategy 2050, as shown in Figure 4 [2].

\section{Implementing green growth plans}

The UAE aspires to become a worldwide centre and a successful model of the new green economy in order to improve the country's competitiveness and long-term 


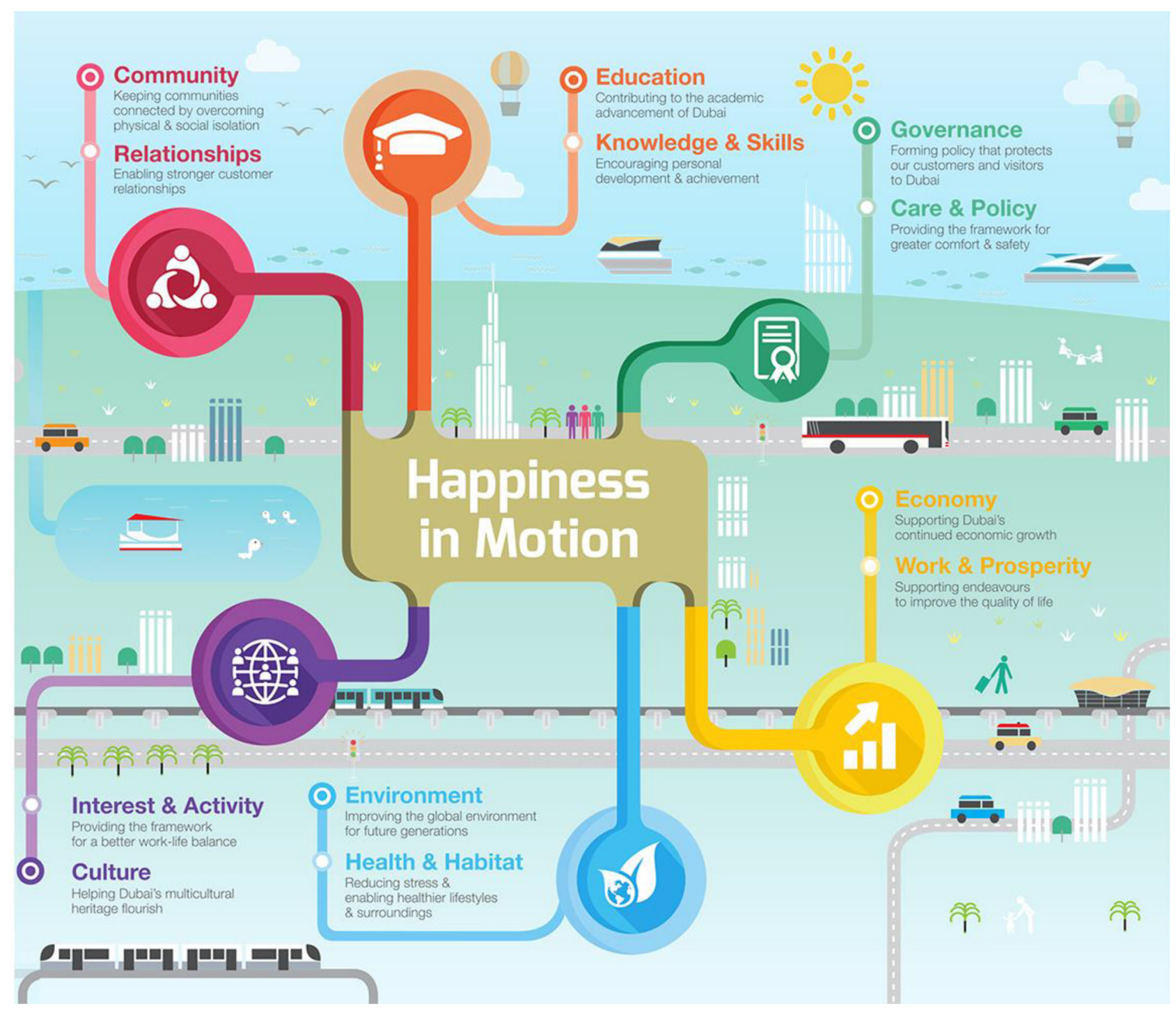

Fig. 7. Dubai plans for happiest city on Earth [6].

development while also protecting the environment for future generations. The UAE Vision 2021 and the Federal Government's strategic plans have placed a strong emphasis on the economy as a major tool for achieving the aim of becoming one of the world's best places to live by 2021 .

UAE aims to showcase the country's major achievements and approach in transforming into a green economy, diversifying economy and energy sources and integrating environmental aspects within all development plans. Green buildings, Figures 5 and 6 are the major approach.

Dubai's Government is aiming to make it the happiest city in the world and UAE has installed computerised "happy metres" to evaluate citizens', residents', and visitors' moods, mainly when they interact with Dubai government services as shown in Figure 7 [6].

\section{Strategic objectives for UAE regulations}

\subsection{Reduce the UAE's environmental footprint}

The UAE's ecological footprint decreased to 7.75 hectares per person last year, down from 11.68 hectares in 2006. The fall was due to the country's acceptance of the Ecological Footprint project, which increased environmental sustainability. After Switzerland and Japan, the UAE is the third country in the world to do so. Five countries - China, the United States, India, Brazil, and Russia - account for 47.2 percent of the world's ecological footprint, according to the 2014 Living Planet Report. Even though UAE urbanisation results in increased carbon emissions and a larger ecological footprint, initiatives to promote a greener economy and environmental policies have helped to improve the situation. The UAE has established requirements to ensure that lighting products imported into the 


\section{Ecological Footprint}

UAE enjoys a high level of human development, but at the cost of a large ecological footprint An Average person in the UAE consumes 10 times more energy than world average, emits 5 times more $\mathrm{CO} 2$ emission and consumes 6 times more electricity than world average

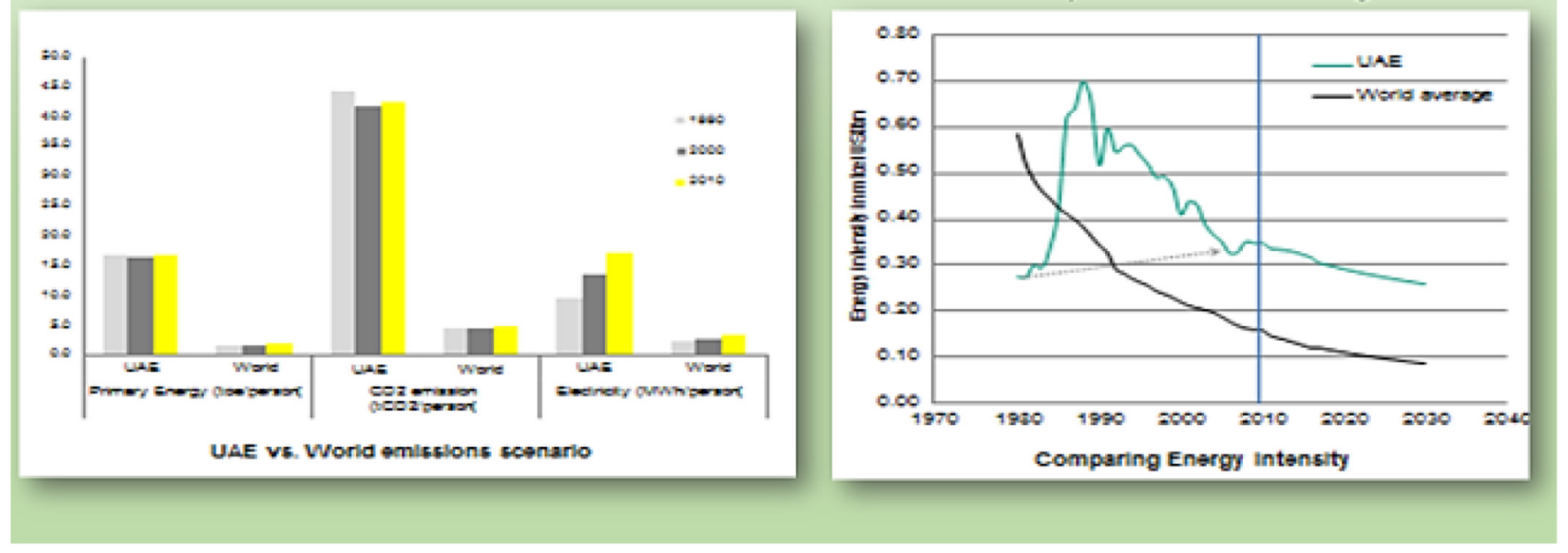

Fig. 8. UAE ecological footprint.

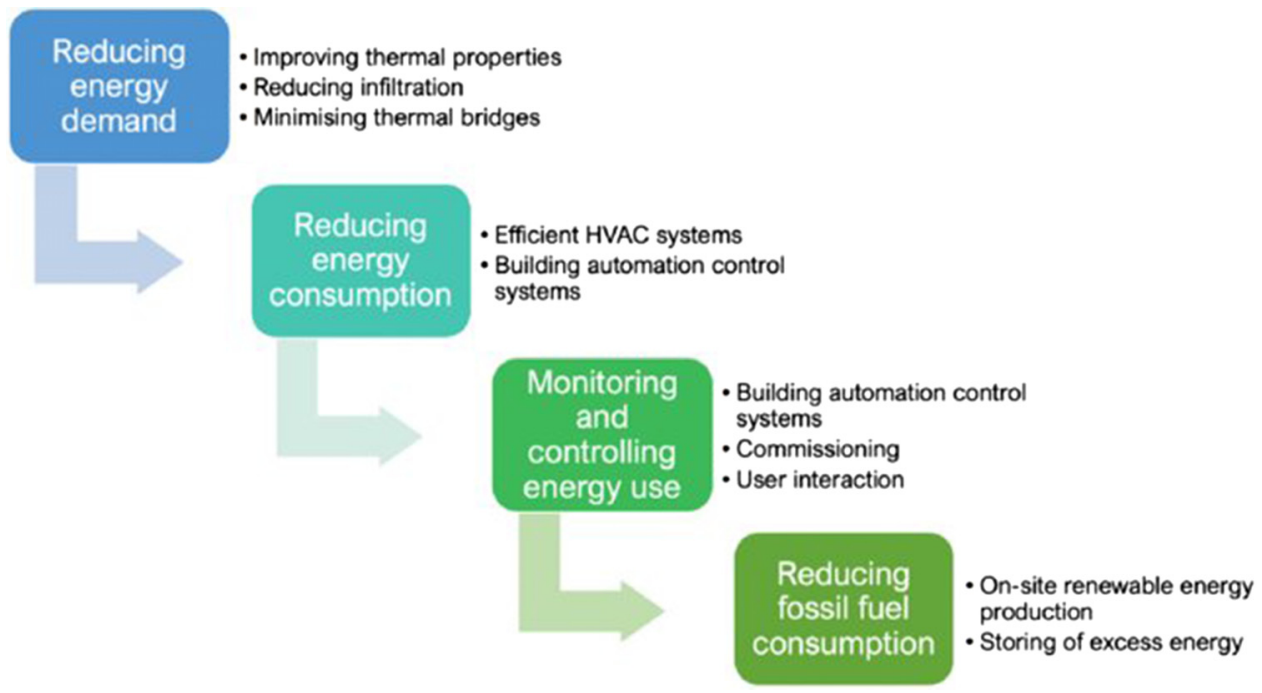

Fig. 9. A Holistic approach for energy efficiency in buildings.

country are energy-efficient, particularly for the housing sector, accounting for $57 \%$ of the country's environmental imprint. The Government also intends to set fuel and vehicle standards in order to cut carbon emissions. Figure 8 shows the UAE ecological footprint.

\subsection{Electrical consumption to be reduced by $20 \%$}

The UAE is aiming to reduce energy consumption by $20 \%$ by 2020 as part of an energy-efficient building project. "Buildings use $70 \%$ of the energy that the country produces", says the UAE. "To get the country green, that needs to target the biggest consumer - the buildings, whether residential or commercial". The Supreme Council of Energy, Electricity, and Water Authority began an initiative in 2008 dubbed the green building project to improve the programme's efficiency. All government buildings were required to follow the programme starting in 2011. However, it expanded this year, requiring all new structures to be energy-efficient [7]. A holistic approach for energy efficiency in buildings is shown in Figure 9 [8]. 
Total Electricity Consumption and Residential Percentage of Total

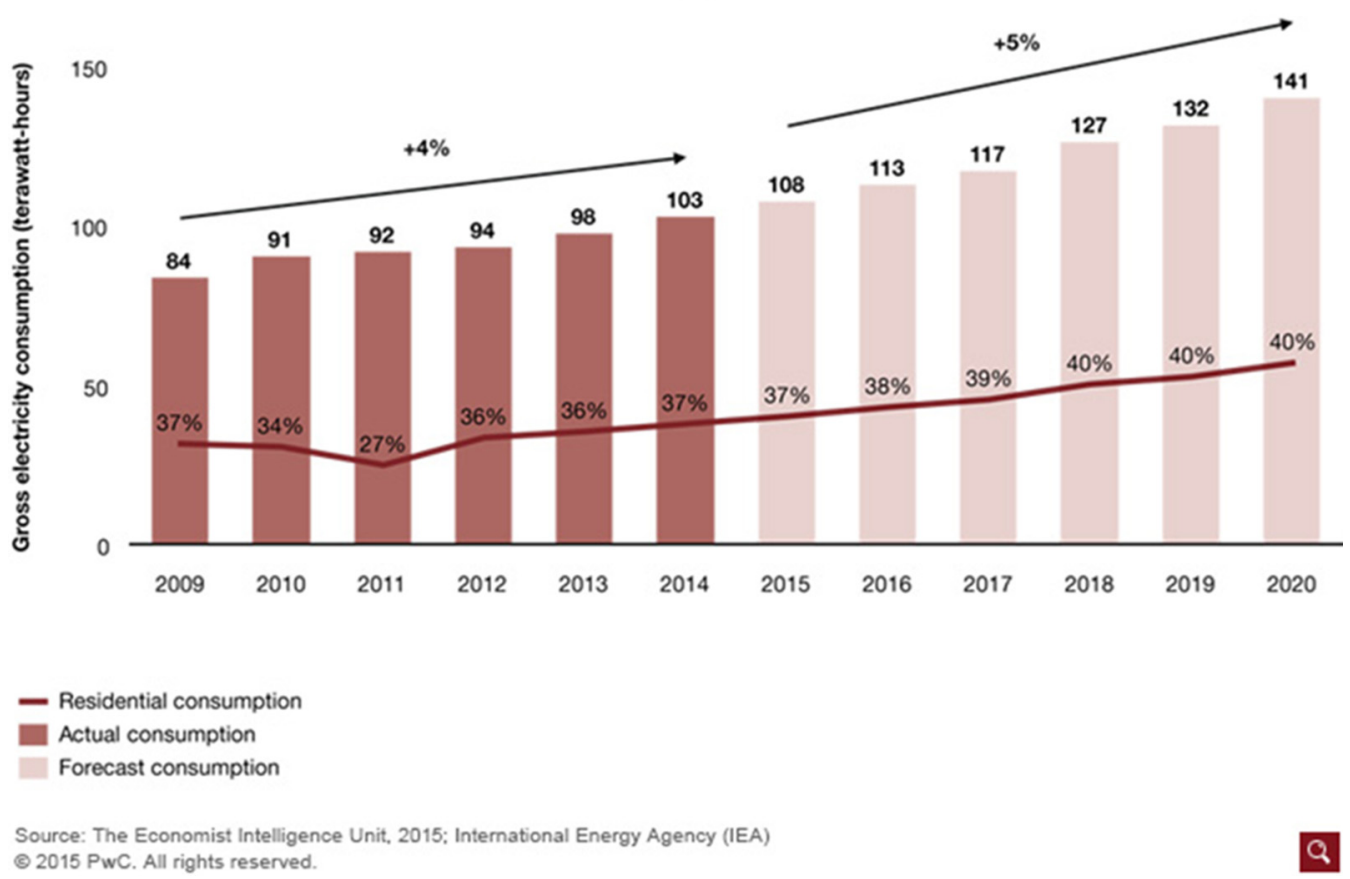

Fig. 10. Total electricity consumption, with the residential percentage of total [9].

The total electricity consumption and residential percentage of total consumption is shown in Figure 10 [9].

\subsection{Water consumption to be reduced by $18 \%$}

Last year, the Federal Electricity and Water Authority (Fewa) saved 53.44 million gallons of water. The $18 \%$ drop in consumption compared to 2014 resulted from a statewide conservation contest that saw homemakers, schools, and mosques compete for the prize. Schools led the way, saving up to 35.34 million gallons of water, or a $25 \%$ reduction compared to 2014 use. Mosques came in second, saving 10.04 million gallons of water, or an $18 \%$ reduction compared to 2014 usage. "Housewives came in third place with 8.1 million gallons of water saved, representing a $9 \%$ reduction in consumption compared to 2014". "The Eastern region (B) led the country in rationing with 13.42 million gallons of water saved, representing a $30 \%$ reduction in consumption than 2014". However, the Western area (A) was able to save 16.71 million gallons of water, which was a 22 percent reduction compared to 2014. The Ministry of Justice in Sharjah, represented by Fujairah, Umm Al Quwain, and Diba Al Hisn, saved 584,186 gallons of water, while the Ministry of Interior in Fujairah saved 188,380 gallons. The Emirates Conservation Award aims to promote water and electricity conservation and instil rationing ideals in future generations. It is available to people of all nationalities. The list is extensive. The Emirates Conservation Award aims to promote water and electricity conservation and instil rationing ideals in future generations. It is available to people of all nationalities. Emiratis, Arabs, and Asians were among the winners. "The aim for conservation was $12 \%$, but some families were able to reduce consumption by up to $60 \%$ and even $80 \%$ ". Fewa had already deployed 25,000 water-saving devices in partnership with strategic partners. The honour, There were 2810 residential participants in the first edition of the Emirates Conservation Award, comprising 506 Emiratis and 2304 expats, but only 1124 were certified. There were 18 homemakers on the list of top winners, three from each of the six regions engaged in the competition [7]. Strategies, policies and activities were enabled, Figure 11 [10].

\section{Smart cities}

In 2014, 85 percent of the UAE's population lived in urban areas, making it one of the world's most urbanised countries. According to the United Nations, the UAE's urban population will continue to expand and account for 91 percent of the country's population by 2050 . As a result, any urban master plan in the UAE must include integrated infrastructure planning. Smart cities allow city planners to improve efficiency at the intersection of different infrastructure sectors [9].

In 2014, 85 percent of the UAE's population resided in urban regions, making it one of the world's most urbanised countries. The urban population is expected to increase further, reaching 91 million people by 2050 . The so-called smart city method may be the greatest way to do this, as it takes advantage of digitalisation and the Big Data generated by metropolitan populations. Although there is no legal definition for the phrase "smart city", it usually 


\section{UAE Enabling Strategies, Policies, Activities}

- UAE energy demand is expected to double by 2020 , water demand is expected to grow by $44 \%$ by 2025 (UNEP, 2013)

- The desalination fuel requirements alone will take up $20 \%$ of the total fuel production by 2030 (MoFA, 2012b)
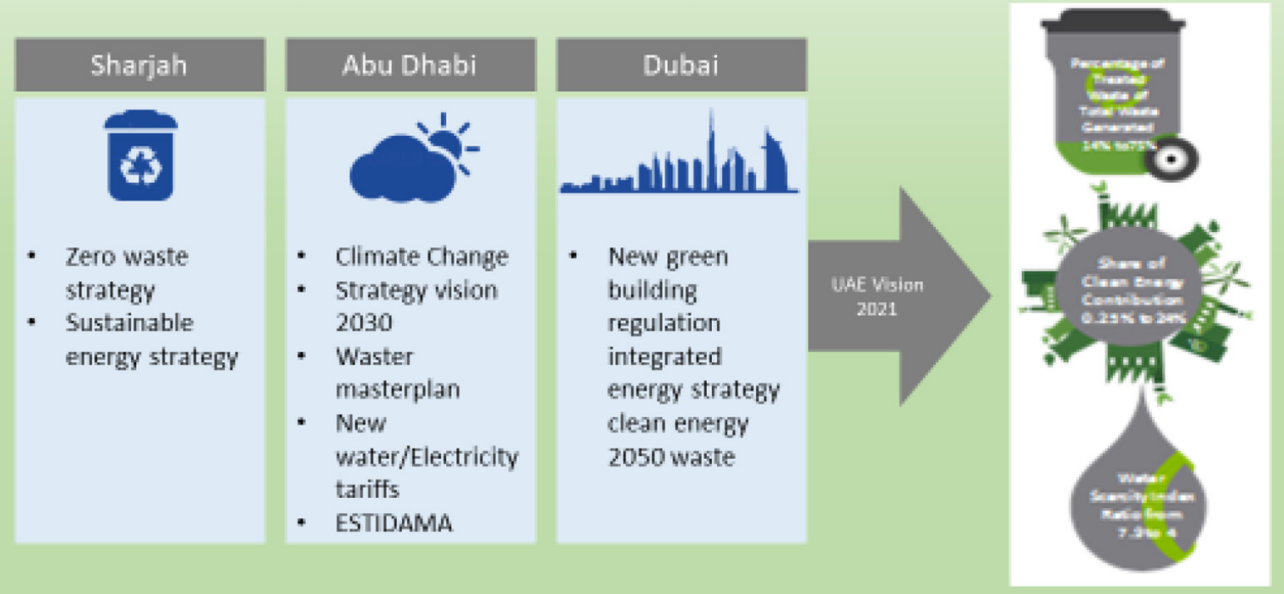

Fig. 11. Water demand growth [10].

refers to integrated infrastructure planning that incorporates digital technologies to improve services and, more importantly for the UAE, cut energy usage.

The transition to smart cities is still in its infancy. The overall relationship between better urban design and the overall sustainability benefit of those projects has yet to be determined. In order to make the shift to smart cities, it is necessary to overcome inertia caused by ingrained habits, whether in terms of urban planning or citizen behaviour. It also necessitates creating and implementing consistent government policies to address the complex changes that smart cities bring about. Despite this, there is widespread agreement that smart cities will increase energy efficiency [9].

Smart cities enable city planners and managers to increase efficiency at the junction of many infrastructure sectors, such as energy, water, transportation, telecommunications, cooling, and waste, by taking a more holistic approach. Because of these benefits, the number of smart cities is expected to treble globally by 2025 [9].

The number of smart cities will more than treble over the next decade (forecast totals) Figure 12.

Smarter urban electricity networks provide the advantage of monitoring usage over time and so encouraging more efficient consumption patterns that result in large reductions in use. For example, in Abu Dhabi, electricity demand has been increasing at a rate of more than $10 \%$ per year, well outpacing the emirate's extraordinary annual population growth rate of $9 \%$.

As a result, the Abu Dhabi government has implemented an advanced metering system with various features and tariffs to encourage users to cut their consumption or transfer it to off-peak hours. Similarly, Dubai has implemented several related projects to significantly reduce electricity use, including smart metering, demand-side management, and distributed generation to encourage energy customers to consume more effectively (which involves generating energy on-site to reduce transmission losses).

These methods saved about 1,100 gigawatt-hours of electricity and 5.4 billion gallons of water between 2009 and 2014 and reduced carbon dioxide emissions by nearly 536,000 tonnes.

Another key part of smart cities is transportation, which has seen significant technological advancements. The UAE is promoting the usage of electric vehicles and developing the infrastructure needed to support them. The country now has 16 electric vehicle charging stations in situ, with more than 100 expected by the end of 2015 . Electric vehicles, on the other hand, are only a minor part of the solution.

To fulfil the transportation needs of a growing urban population, the UAE must address more significant issues such as improving the fuel efficiency and emissions of imported automobiles, persuading citizens that they may not need a car, and reducing reliance on cheap gasoline.

As a result, public awareness initiatives should be included as part of a smart city programme, as they are a gentler way of influencing citizens' behaviour. Budgets for such efforts have already been set up in the UAE. The Emirates Energy Award, for example, was established by the Dubai Supreme Council of Energy and offered monetary prizes for outstanding work in public and private sector projects of various kinds.

The Dubai Electricity and Water Authority (DEWA) has also sponsored customer awareness programmes, which have convinced households and businesses to turn up the 


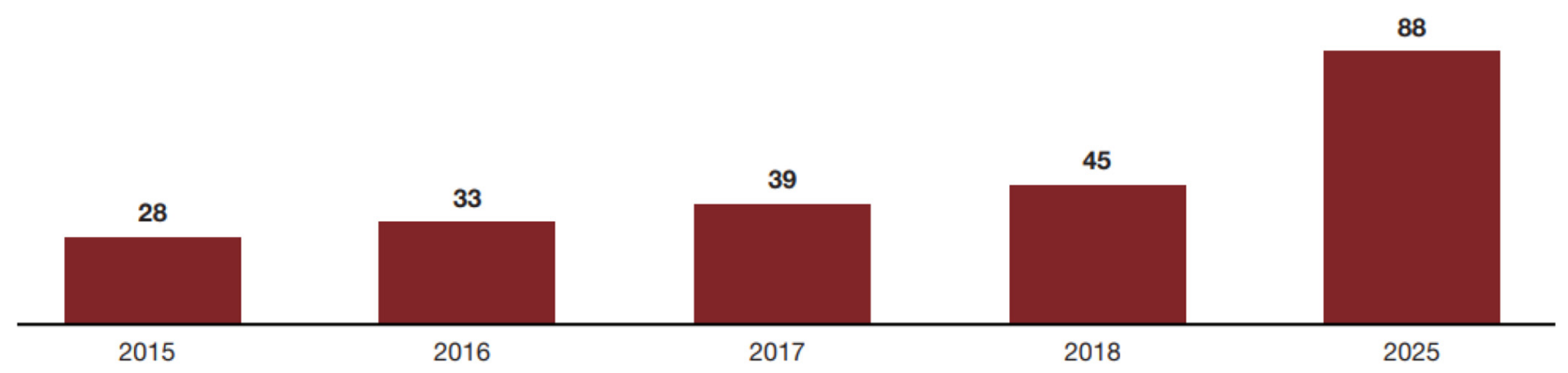

\section{Emission of $\mathrm{CO} 2$ from building sector in UAE.}

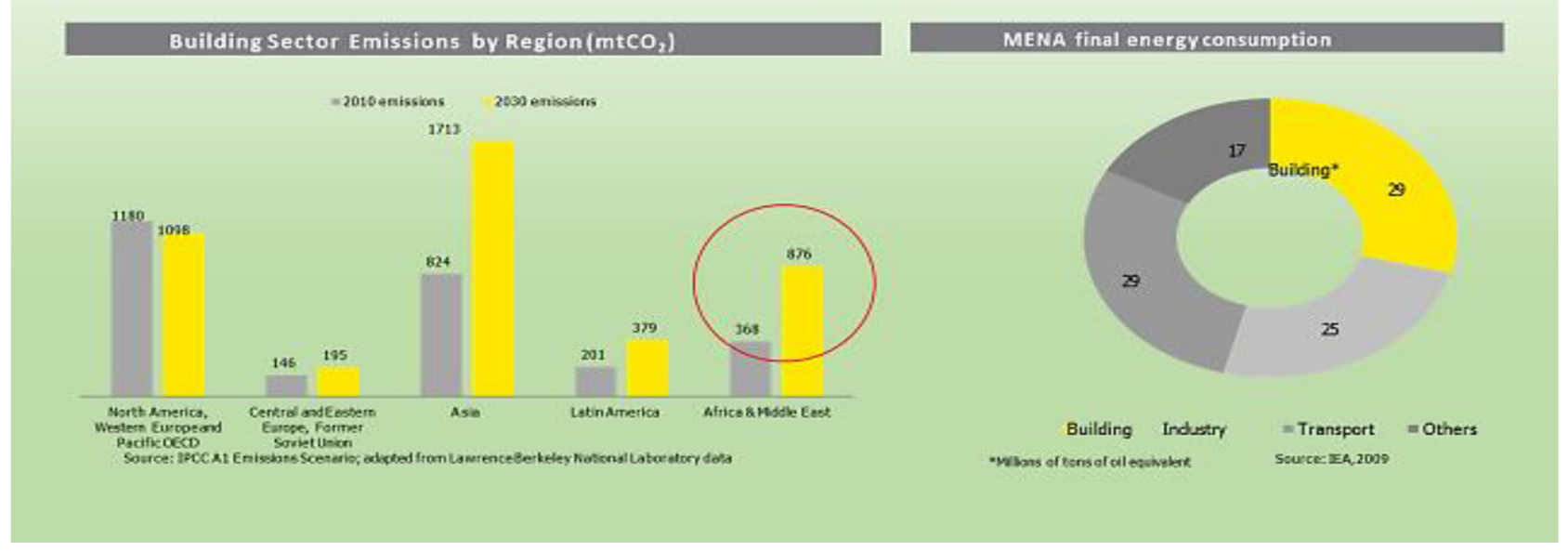

Fig. 13. $\mathrm{CO}_{2}$ emission from building sector in UAE.

temperature on their air conditioners. Since 2009, DEWA's campaign has saved a total of more than 600 million AED (US\$163 million) [9].

\section{Building efficiency}

Building efficiency, sometimes known as "green" or "sustainable" building, refers to structures designed and constructed with energy efficiency as a primary design constraint. Buildings have a considerable contribution to $\mathrm{CO}_{2}$ emissions, Figure 13. The idea is to lessen buildings' environmental effects while also improving the well-being of their tenants.

A variety of building efficiency measures are already in place in the UAE. For example, in Abu Dhabi, a programme called Estidama (the Arabic word for sustainability) oversees building design, construction, and operation through a series of approvals. Estidama also has a rating system known as the
"Pearl Rating System", which assesses the sustainability of villas, buildings, and communities. The Government of Dubai has created green building standards and criteria that address planning, resource use, material selection, and waste disposal.

The standards, in particular, are designed to improve the sustainability performance of buildings across their entire life cycles, from design to construction, operation, and eventual demolition.

\section{Detailed regulations and frameworks}

More specific policies and procedures governing energy efficiency in buildings will need to be developed by government bodies across the UAE.

More specific norms and procedures governing energy efficiency in buildings, particularly during construction, will need to be developed by government bodies across the UAE. These regulations can take a variety of forms, 


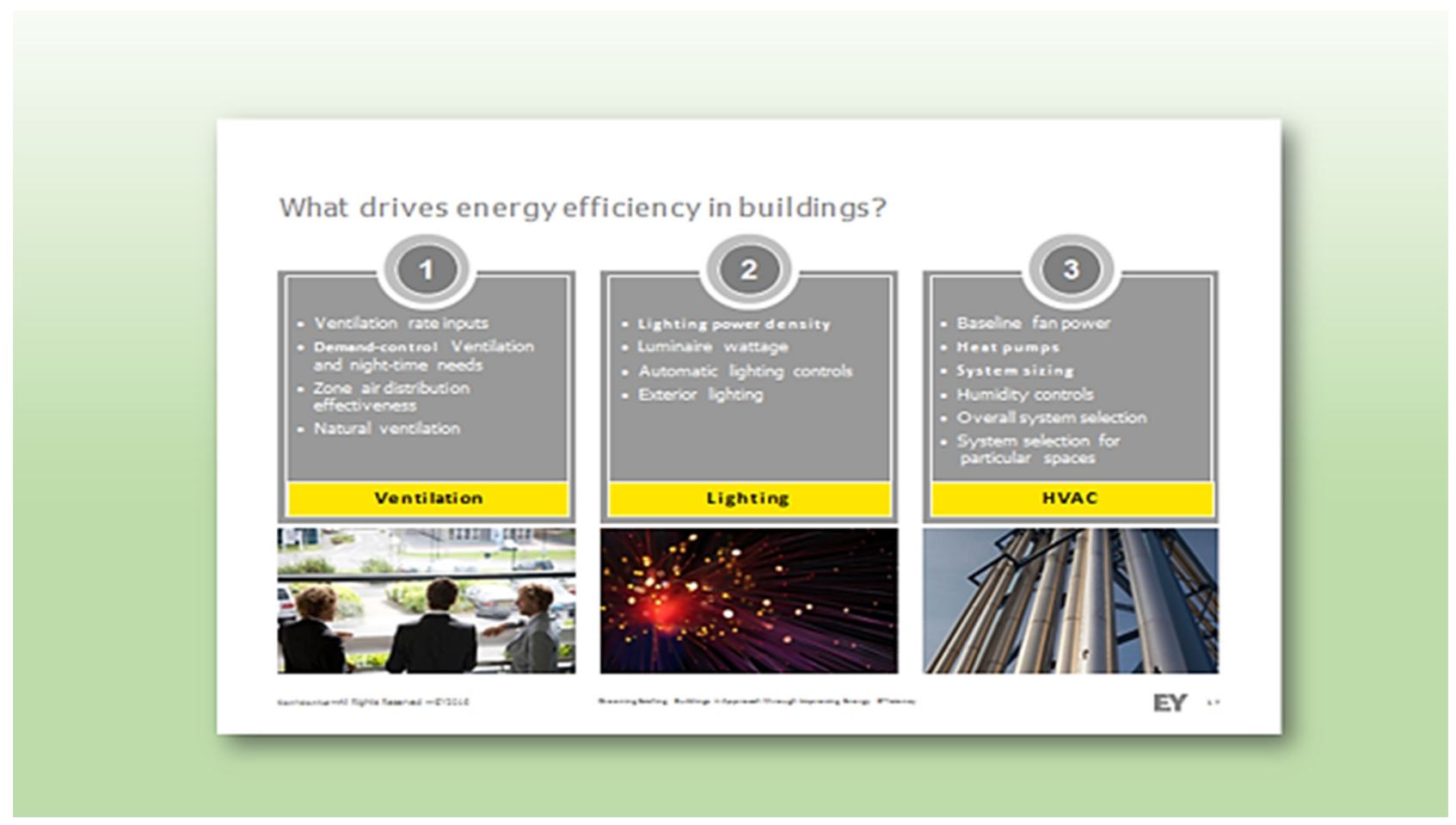

Fig. 14. Energy efficiency drivers in buildings.

including requiring advanced modelling and simulations to predict the energy consumption footprint before construction (a tool known as building information modelling); requires advanced modelling and simulations to anticipate the energy consumption footprint prior to construction; and mandating procurement methods that consider the entire life-cycle cost rather than simply the initial construction cost [11]. (a tool known as building information modelling). Furthermore, district cooling has the potential to improve the energy efficiency of UAE urban areas significantly. 4 Building cooling currently accounts for over $70 \%$ of the GCC's peak electricity demand. District cooling is a network-based technology that employs centralised infrastructure to cool numerous buildings at the same time. This method is substantially more efficient than the current approach to air conditioning because it pools the demand for colder air. Increased utilisation of district cooling would alleviate the cooling load's impact on overall energy consumption. Various regulatory authorities in the United Arab Emirates are looking into ways to mandate and control district cooling, and the technology should be addressed in any new urban design idea [12]. Points that drive energy efficiency in buildings are shown in Figure 14.

Improved marketing and awareness efforts are also required to urge real estate developers to increase the energy efficiency of their projects without the need for legislation. Such campaigns can, for example, highlight the efficiency benefits of new technologies, designs, and materials, evaluate building performance among similar buildings and grant energy performance certificates with incentives for builders [9].
Finally, the Government should promote the adoption of cutting-edge building materials, technologies, and systems. Advanced concrete mixes, wall insulation, glass glazing, and coatings tailored to the region's needs would significantly increase building efficiency. These materials are already in use in other markets because they improve building efficiency immediately after installation. During the design and construction of new projects, the UAE government should ensure that certain materials are considered - or required — by the Government. Even after construction is completed, projects can still benefit from increased energy efficiency thanks to tools like advanced building automation, integrated applications, and monitoring and reporting, which raise energy awareness among occupants and facility managers while drastically reducing consumption. Figure 15 presents the footprint demand by sector. In 2019, about 14 million tonnes of emissions were removed, reducing $22 \%$ compared to the previous year. The results attained exceeded the goals set forth in the Dubai Carbon Abatement Strategy, which calls for a 16 percent reduction in carbon emissions by 2021 [13].

\section{Implementations}

Although BIM has been used in the UAE for many years, its use in municipal projects is still quite limited. There are initiatives in place, such as the Dubai Municipality's mandate to use BIM for high-capacity projects. However, adoption remains low in projects, particularly at the municipal level. The study shows that stakeholders are aware of BIM, but that 


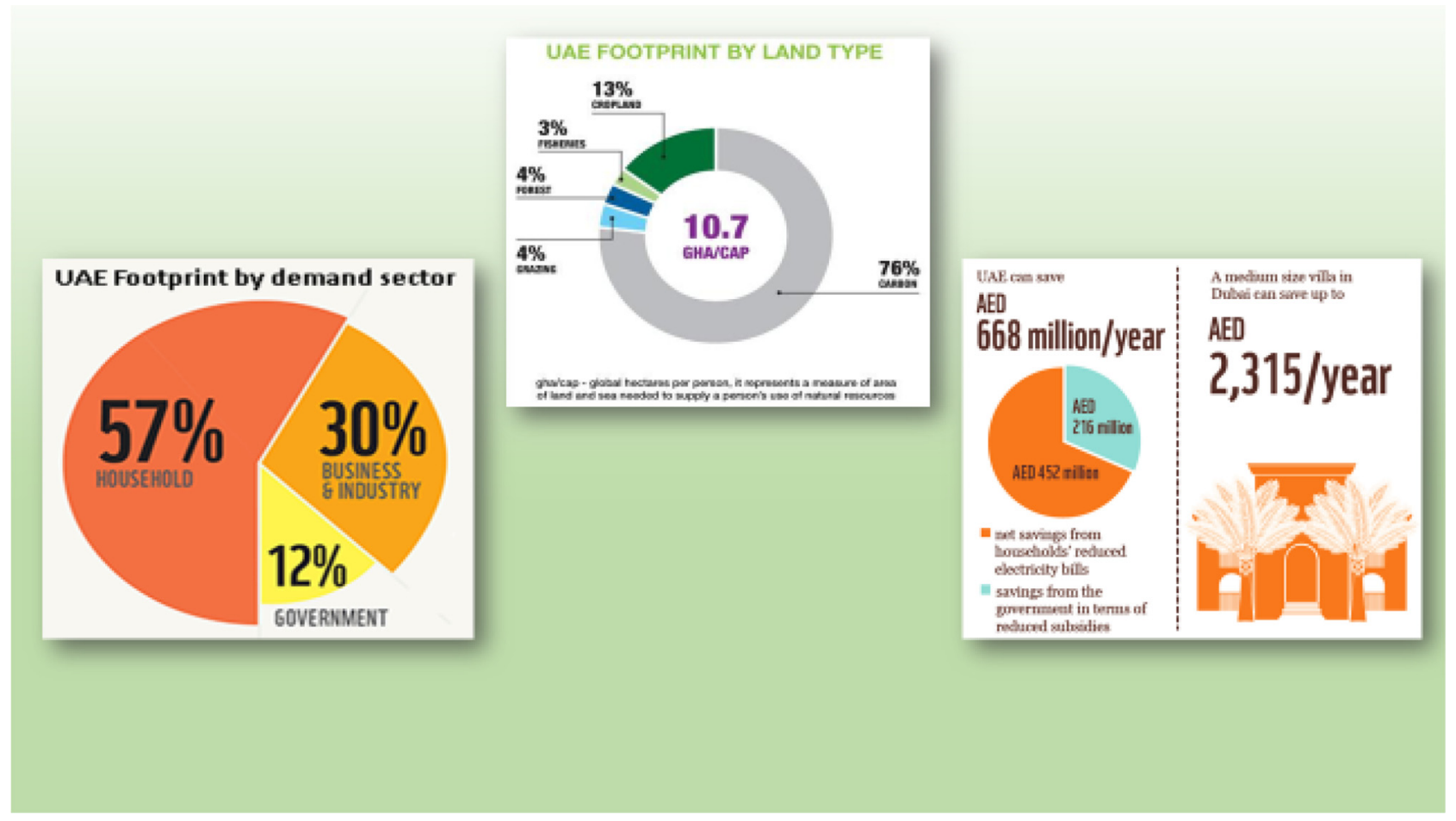

Fig. 15. UAE footprint by demand and land sectors [17-19].

adoption is restricted. The survey also revealed that the perceived BIM use occurs primarily during the design stage. Furthermore, it is noted that while technological preparedness exists in the study environment, people and processes do not [14]. Moreover, District Cooling, which was first used in Dubai in 1999, provides several advantages over traditional cooling systems, including being more ecologically friendly and efficient. District cooling decreases the temperature of the air entering through the air-conditioning unit by pumping chilled water from a central facility to buildings and villa complexes through underground insulated pipes. District cooling in Dubai seeks to cut power usage and be more energyefficient through this procedure [15]. Expo 2020 will be held in Dubai's South District. Expo 2020 has several topics, one of which is sustainability. Expo will consume half of its electricity during the event from $100 \%$ renewable sources, half of which will be generated on-site. The great majority of the materials used in permanent site development will be reused in infrastructure projects [16].

\section{Conclusion}

This paper explores the facts on how Dubai has always encouraged achieving healthy and sustainable development in all sectors, explicitly building construction. It has worked to preserve a balance between socioeconomic development and environmental protection, and it continues to do so. Initiatives have been announced and included in the national vision, which states that the government's top aim is to develop Dubai into a smart city with an environmentally friendly economy. This is part of a plan to make it the world's most sustainable metropolis by 2021. The innovative initiatives, technologies, materials, tactics, obstacles, and challenges that Dubai has faced in achieving sustainable smart city goals are also highlighted in this article. Green buildings and renewable energy systems are two examples of options that could significantly reduce carbon emissions. Building energy efficiency assessments are an essential tool for ensuring that proposed strategies have the intended consequences. It has been determined that the UAE is working on a good programme to reduce its carbon footprint. Energy efficiency was not a pressing concern in the UAE for decades due to the abundance of widely accessible hydrocarbon resources. However, opinions have shifted as a result of sustained population and economic expansion. Sustainability is a vital issue today, and it is becoming more serious by the year. The moment has come for the UAE government to step in and help the country build a more sustainable future. The UAE can ensure that it serves the demands of its inhabitants while also conserving the environment for future generations by using other countries' experiences and focusing on the priorities highlighted in this paper.

\section{References}

1. Dm.gov, DUBAI AIR QUALITY STRATEGY. (2021). Available at: http://www.dubaiairenvironment.dm.gov.ae/ air_quality_strategy [Accessed 10 July 2021]

2. DEWA, Sustainability Report 2019, Dubai Electricity \& Water Authority, Dubai, UAE, 2019 
3. K. Kaygusuz, Energy for sustainable development: a case of developing countries, Renew. Sustain. Energy Rev. 16, 11161126 (2012)

4. Oecd, Climate Action - CAN CHANGE OUR LIVES FOR THE BETTER. (2020). Available at: https://www.oecd. org/stories/climate-25-actions / [Accessed 21 October 2021]

5. Vision2021.ae, UAE VISION. (2018). Available at: https:// www.vision2021.ae/en/uae-vision [Accessed 21 Ovtober 2021]

6. K. Rooney, 5 things you may not know about Dubai. (2019). Available at: https://www.weforum.org/agenda/2019/11/ dubai-shopping-technology-film-clooney-tourism/ [Accessed 11 July 2021]

7. Al-Dabbagh, Am. Sci. Res. J. Eng. Technol. Sci. 74, 170-188 (2020)

8. L. Felius, F. Dessen, B. Hrynyszyn, Retrofitting towards energy efficient homes in European cold climates - a review, Energy Effic. 13, 101-25 (2019)

9. A. Tayar, P.O. Karlsson, C. Decker et al., Energy Efficiency in the UAE - Aiming for Sustainability. Available Online At: https://www.strategyand.pwc.com/m1/en/reports/energyefficiency-in-the-uae.pdf. (11 July 2021, date last accessed)

10. UNEP, United Nations Environmental Program annual report (2013)

11. BRE, Building Energy Modelling (2021). Available at: https://www.bregroup.com/a-z/building-energy-modelling/ [Accessed 10 July 2021]

12. Stalawfirm, Ananalysis of medical Negligence Claims and Liability in Gulf Countries (2018). Available at: https:// www.stalawfirm.com/en/blogs/view/medical-negligenceclaims.html [Accessed 11 July 2021]

13. A. Oommen, Dubai reduced 14 million tonnes of carbon emissions in 2019 (2020). Available at: https://www. constructionweekonline.com/business/267236-dubai-reduced14-million-tonnes-of-carbon-emissions-in-2019 [Accessed 6 July 2021]

14. S. Venkatachalam, An exploratory study on the building information modeling adoption in United Arab Emirates municipal projects - current status and challenges, MATEC Web Conf. 120, 2015 (2017)

15. Bayut, The complete list of residential areas in Dubai with district cooling. (2021). Available at: https://www.bayut. $\mathrm{com} / \mathrm{mybayut} /$ district-cooling-areas-dubai/ [Accessed 21 October 2021]

16. U.ae, Smart sustainable cities. (2021). Available at: https:// u.ae/en/about-the-uae/digital-uae/smart-sustainable-cities [Accessed 21 October 2021]

17. Footprintwork.org, United Arab Emirates. (2018). Available at: https://www.footprintnetwork.org/2015/11/18/unitedarab-emirates/ [Accessed 3 July 2021]

18. E.N. Udemba, Nexus of ecological footprint and foreign direct investment pattern in carbon neutrality: new insight for United Arab Emirates (UAE), Environ. Sci. Pollut. Res. Int. (2021)

19. R. AL-Dabbagh, Why do we need to reduce the carbon footprint in UAE? in Sustainable Building for a Cleaner Environment. Innovative Renewable Energy, edited by A. Sayigh (Springer, Cham, 2019)

Cite this article as: Riadh AL-Dabbagh, Dubai, the sustainable, smart city, Renew. Energy Environ. Sustain. 7, 3 (2022) 